\title{
THE PRESENCE OF ANTIMIONY IN BOTTLED BEVERAGES.
}

\author{
By JOHN C. THRESH, M.D., D.SO., ETC. \\ Medical Officer of Health, Essex County Council, Lecturer on Public Health, \\ London Hospital Medical College.
}

Mr. Pond, of Liverpool, has recently directed the attention of the profession to the presence of antimony in beverages sold in bottles provided with stoppers which are made to fit tightly by aid of rubber rings, the antimony being derived from the rings, all of which contain a large proportion of sulphide of that metal. Mr. Pond thinks that the presence of antimony compounds in such beverages may be a cause of appendicitis, and possibly of other obscure internal affections. In his opinion the ingestion of repeated small doses of antimony may lead to $(a)$ weakening of the muscular coat of the cæcum and vermiform appendix and the resulting appendicitis; (b) weakening of the muscular coat of the stomach and dilatation of that organ; $(c)$ irritation of the mucous membrane of the stomach and intestines, resulting in some cases in the production of gastric and intestinal ulcers; and $(d)$ weakening of the muscular coat of the intestine with the production of constipation. At present proof is wanting that small doses of antimony can produce any such effects, since Mr. Pond's opinions are based only on a few cases which have occurred in his private practice and require confirmation. It is possible, however, if beverages supplied in such bottles as those to which I have referred, contain appreciable traces of antimony, that their use may be attended with danger to health, and the experiments shortly to be recorded were made to ascertain whether such beverages were likely to contain antimony or not. The information available as to the effects due to minute traces of this poison is very meagre. Allbutt* says that towards antimony people exhibit a peculiar idiosyncrasy. Some are early affected by the minutest dose, others are extremely tolerant of it. Exceedingly small doses frequently administered cause a metallic taste in the mouth, with frequent vomiting, great prostration, clammy sweats, and feeble pulse. In some cases vomiting may be absent. Lehmant states that 1 to 10 mgrams of tartar emetic taken daily may cause chronic illness. Antimony, like arsenic, tends to accumulate in the nervous tissues, but no records appear to exist of its having produced any symptoms of peripheral neuritis, such as those caused by arsenic. It is excreted by the urine, and it is probable * "System of Medicine," Vol. II., 942. † "Practical Hygiene," Vol. II., 382. 
that in any case of suspected poisoning, antimony would be found in this fluid if this metal were the cause of the symptoms. Unfortunately, in Mr. Pond's cases no such examination appears to have been made. From the above evidence it seems possible that the frequent ingestion of even a milligram or less of antimony may exert evil effects. The following research was made, therefore, to ascertain whether beverages in bottles with rubber on the stoppers did contain even so small a quantity of antimony as that above indicated. Samples of various beverages were purchased in the East End of London, a dozen of each kind (except wine), and each was divided into half dozens, one with rubber stoppers showing least signs of wear, and the other with stoppers showing greatest signs of wear. These were examined separately. The liquid was passed through a small filter, and the filtered liquid and the residue on the filter paper were both examined.

Before commencing the actual examination for antimony, a series of experiments were conducted to ascertain the best method of procedure. Marsh's test as applied for arsenic suggested itself as possibly being the most delicate for quantitative and qualitative work, but it was soon found that different results were obtained with the same quantity of antimony according to the character of the solution, less marked results being obtained in the presence of saccharine and other organic matter. The same proved to be the case with the zine platinum test, but to a much less marked extent, and even in saccharine liquids ' 1 milligram (one-sevenhundredth of a grain) could easily be detected. The latter test was therefore employed for quantitative estimation, and Marsh's test for detection. The liquids were evaporated to a low bulk, and portions poured into the hydrogen generating bottle of the Marsh's apparatus. If after passing for half an hour no deposit was found in the ignited tube, no appreciable quantity of antimony was present. No deposit was obtained in any case, so that all the liquids appeared to be free from antimony in solution. The filter residues were treated with strong nitric acid, evaporated to dryness, and the residue taken up with a little hydrochloric and tartaric acid slightly diluted. The liquid was placed in a platinum dish and a fragment of elean zine added. In the presence of 1 milligram $\mathrm{Sb}$ a brown stain appears on the platinum in 15 to 30 minutes. The colour of this stain can be matched by using the same volume of a solution of tartar emetic, and varying this in strength.

The results obtained are recorded in the subjoined table. In no case was a piece of rubber found of such a size as to be recognizable by the naked eye, and in no instance did the antimony present in a bottle of liquid amount to 1 milligram, or $\frac{1}{50}$ of a grain. It is noteworthy, however, that in 3 cases where the rubber round the 
stopper showed signs of wear, traces of antimony were found in the deposit filtered out of the liquid, whereas such a trace was only found once where the stoppers showed no signs of wear. It is almost certain that on occasions large pieces of rubber will become detached, as this material becomes less eliaste, if not actually brittle, with age.

TABLE OF EXPERIMENTAL RESULTS.

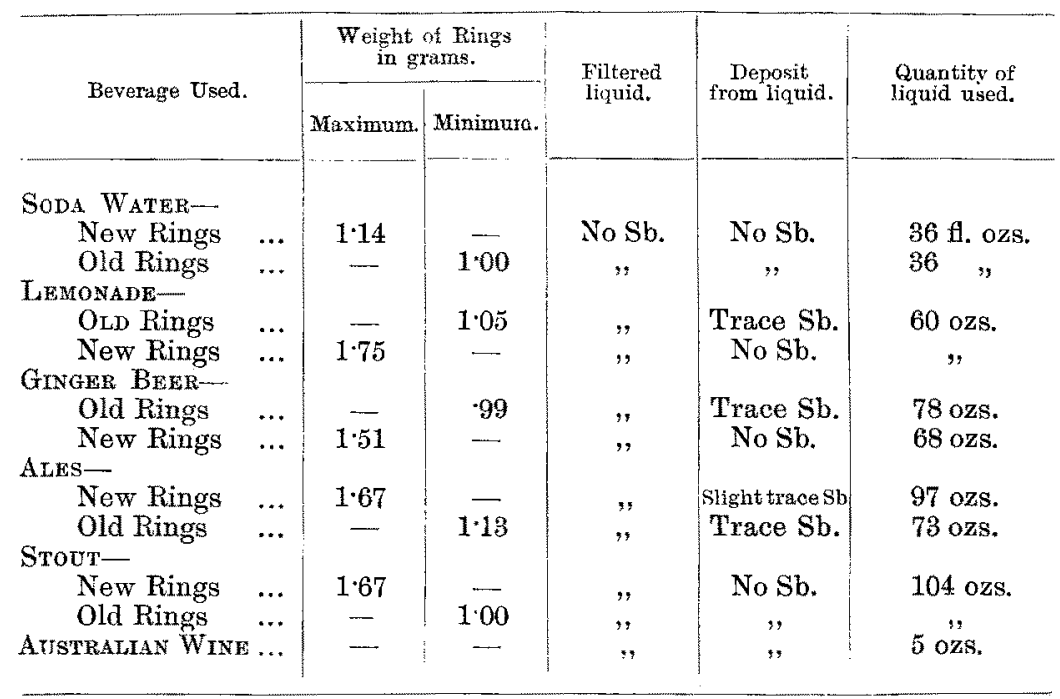

Further experiments were made with the rings $(a)$ by boiling in soda water; $(b)$ by boiling in a solution of tartaric acid. The results were as under :-

1. The filtered soda water contained no antimony in solution.

2. The deposit filtered out contained an average of 1 milligram ( $\frac{1}{i} \frac{2}{6}$ grain) of antimony per rubber ring.

3. The tartaric acid solution contained about 7 milligram ( $\frac{1}{100}$ grain) of antimony in solution. The amount detached and remaining insoluble was not determined.

The solubility of the antimony sulphide contained in the rubber appears therefore to be so slight that the only danger to be apprehended is from detached particles, and especially if old rings are used.

As antimony is undoubtedly a cumulative poison, causing serious effects even when very small doses are frequently administered, and as particles of rubber containing from 15 to 25 per cent, or possibly more, of antimony sulphide are frequently found in beverages supplied in bottles with such rubber on the stoppers, their use cannot be considered as entirely without danger, and some form of rubber free from such a poisonous ingredient should be employed, or some substitute for rubber be adopted. 
It is possible that the danger has been exaggerated, but this can only be determined by continued observation, and it is desirable, in the interest of the public health, that medical men, and especially Medical Officers of Health, should bear this possible danger in mind, and report any observations tending to prove or disprove the opinions expressed by Mr. Ponds.

The Adulteration of Washing Soda.-Mr. A. W. Stokes. F.C.S., Public Analyst for the Borough of Paddington, has reported that six out of nine samples of washing sodid purchased for analysis contained Glauber's salts in proportions ranging from 42 to 70 per cent-that is to say, two-thirds of the samples purchased contained not even half their weight of real soda. In other words, in the case of these adulterated samples, no less than 54 per cent of the stuff sold as soda was useless material put in to make weight, which would be actually in the way in laundry work, and which costs the manufacturers less than one-third of the price of the real article. A test case was taken against one vendor, an attempt being made to show that soda should rank as food, owing to its use in boiling vegetables, etc., but this was over-ruled by the magistrate and the case was dismissed. A strong argument would appear to be made out for the widening of the scope of the Food and Drugs Acts, so as to include articles in such extensive use for a variety of domestic purposes as washing. soda.

A National Water Board Proposed.-Professor G. Sims Woodhead read a paper on the "Water Supply in Rural Districts," before a meeting of the Royal Sanitary Institute, held at Cambridge. He said the problem of the water supply in rural districts was a much more pressing one than that of the supply to the large manufaeturing towns. One was simply horrified at the shifts that had to be made in rural districts to obtain water even of moderately good quality. It was the duty of the larger communities in their own interest to take up the question. An agricultural district far away from London might, through the contaminated water supply, become a centre of infection to the area in London to which milk from that district was distributed; and what applied in such an extreme case might apply still more directly to other agricultural areas and towns. So firmly convineed was he of this that he was gradually coming to be of opinion that the question of water supply was one to be settled, not by individual communities, but by a National Water Board, with county committees. The selfishness of communities should be counteracted by the constitution of some central organization, which should be empowered to control water supplies, and which should also be empowered to prevent the contamination of any possible supply with sewage. He was aware that certain well-informed authorities maintained that rivers were the natural drains ; but, with Lincoln before them, they were apt to be very sceptical on the point. Rivers were natural water supplies, and they had only been converted into drains because people had not had foresight enough to see that in time they would not have sufficient water for the growing population without them. Whatever difficulties they might have to overcome in the way of obtaining water, of storing, filtering, and distributing it, the key to the whole position was combination, co-operation, and centralization. 